\title{
GCU
}

Glasgow Caledonian

University

University for the Common Good

\section{Prehabilitation exercise therapy before abdominal aortic aneurysm repair}

Fenton, Candida; Abaraogu, Ukachukwu Okoroafor; Tan, Audrey R.; McCaslin, James E.

\section{Published in:}

Cochrane Database of Systematic Reviews

DOI:

10.1002/14651858.CD013662

Publication date:

2020

Document Version

Publisher's PDF, also known as Version of record

Link to publication in ResearchOnline

Citation for published version (Harvard):

Fenton, C, Abaraogu, UO, Tan, AR \& McCaslin, JE 2020, 'Prehabilitation exercise therapy before abdominal aortic aneurysm repair', Cochrane Database of Systematic Reviews, no. 7, CD013662.

https://doi.org/10.1002/14651858.CD013662

\section{General rights}

Copyright and moral rights for the publications made accessible in the public portal are retained by the authors and/or other copyright owners and it is a condition of accessing publications that users recognise and abide by the legal requirements associated with these rights.

Take down policy

If you believe that this document breaches copyright please view our takedown policy at https://edshare.gcu.ac.uk/id/eprint/5179 for details of how to contact us. 


\section{Cochrane}

Library

Cochrane Database of Systematic Reviews

\section{Prehabilitation exercise therapy before abdominal aortic aneurysm repair (Protocol)}

Fenton C, Abaraogu UO, Tan AR, McCaslin JE

Fenton C, Abaraogu UO, Tan AR, McCaslin JE.

Prehabilitation exercise therapy before abdominal aortic aneurysm repair (Protocol).

Cochrane Database of Systematic Reviews 2020, Issue 7. Art. No.: CD013662.

DOI: 10.1002/14651858.CD013662.

www.cochranelibrary.com

Prehabilitation exercise therapy before abdominal aortic aneurysm repair (Protocol) 
TABLE OF CONTENTS

HEADER 1

ABSTRACT

BACKGROUND

OBJECTIVES

METHODS

ACKNOWLEDGEMENTS

REFERENCES

ADDITIONAL TABLES

APPENDICES

HISTORY

CONTRIBUTIONS OF AUTHORS

DECLARATIONS OF INTEREST

SOURCES OF SUPPORT 
[Intervention Protocol]

\section{Prehabilitation exercise therapy before abdominal aortic aneurysm repair}

Candida Fenton¹, Ukachukwu Okoroafor Abaraogu²,3, Audrey R Tan4, James E McCaslin 5

1Usher Institute of Population Health Sciences and Informatics, University of Edinburgh, Edinburgh, UK. 2Department of Physiotherapy and Paramedicine, School of Health and Life Sciences, Glasgow Caledonian University, Glasgow, UK. ${ }^{3}$ Department of Medical Rehabilitation, University of Nigeria, Nsukka, Nigeria. ${ }^{4}$ Institute of Health Informatics Research, University College London, London, UK. 5 Northern Vascular Centre, Freeman Hospital, Newcastle upon Tyne, UK

Contact address: Candida Fenton, Candida.Fenton@ed.ac.uk.

Editorial group: Cochrane Vascular Group.

Publication status and date: New, published in Issue 7, 2020.

Citation: Fenton C, Abaraogu UO, Tan AR, McCaslin JE. Prehabilitation exercise therapy before abdominal aortic aneurysm repair (Protocol). Cochrane Database of Systematic Reviews 2020, Issue 7. Art. No.: CD013662. DOI: 10.1002/14651858.CD013662.

Copyright (c) 2020 The Cochrane Collaboration. Published by John Wiley \& Sons, Ltd.

\section{A B S T R A C T}

\section{Objectives}

This is a protocol for a Cochrane Review (intervention). The objectives are as follows:

To assess the effects of exercise programmes on perioperative and postoperative morbidity and mortality associated with abdominal aortic aneurysm repair. 


\section{B A C K G R O U N D}

\section{Description of the condition}

An abdominal aortic aneurysm (AAA) is defined as an abnormal dilation in the diameter of the abdominal aorta of $3 \mathrm{~cm}$ or more (Hirsch 2006; Moll 2011). Most AAAs are asymptomatic and are frequently discovered incidentally during imaging or clinical examination for other conditions (Brown 2012). As well as having many risk factors in common with atherosclerosis (including tobacco smoking, advanced age, male sex, and hypertension), genetic factors and family history are likely to influence the development of abdominal aneurysms (Blanchard 2000; Larsson 2009; Lederle 1997).

The natural history of AAA is expansion (which in some cases causes the aneurysm to become symptomatic) and eventually, acute rupture. In the case of acute rupture, the classical presentation is the triad of sudden, severe abdominal or back pain (or both), a pulsatile abdominal mass and haemodynamic collapse. Mortality among people presenting with a ruptured aneurysm is high (particularly if the rupture occurs out of hospital), and even for those who do make it to hospital and undergo emergency surgery, mortality is approximately 35\% (Gunnarsson 2016; Schermerhorn 2012; Sweeting 2015).

The average annual progression in diameter of small aneurysms $(\leq 5.5 \mathrm{~cm})$ is estimated to be between 2.0 and $3.0 \mathrm{~mm} /$ year, while progression is greater for aneurysms with a larger initial diameter (Bown 2013; Moll 2011). The risk of rupture increases with the diameter of the aneurysm, particularly above a diameter of approximately $5.5 \mathrm{~cm}$ (Powell 2008; Powell 2011).

Previously, the prevalence of AAA has been reported to range from $1.3 \%$ in women aged 65 to 80 years, to between $4 \%$ and $7.7 \%$ in men aged 65 to 80 years (Ashton 2002; Ashton 2007; Lindholt 2005; Nordon 2011; Norman 2004; Scott 2002). The annual incidence of AAA in Western populations has been estimated at between $0.4 \%$ and $0.67 \%$ (Forsdahl 2009; Lederle 2000; Nordon 2011; Vardulaki 1999), but may be lower for Asian populations (Spark 2001). More recent evidence suggests that AAA incidence is decreasing, most likely because of a reduction in tobacco smoking (Anjum 2012). The current prevalence rates are closer to $1.5 \%$ for men aged 65 and $0.7 \%$ for women over 60 years old (Jacomelli 2016; Svensjö 2014; Ulug 2016). There has also been discussion on the importance of the 'subaneurysmal' aorta (diameter $2.5 \mathrm{~cm}$ to $2.9 \mathrm{~cm}$ ), since twothirds of these will become aneurysmal over a period of five years (Wild 2013).

In asymptomatic people in whom AAA is suspected clinically, a definite diagnosis can be made using abdominal ultrasound to measure the diameter of the aneurysm (Moll 2011). More detailed information regarding the anatomy and relation to renal and visceral vessels can be obtained from computerised tomography (CT) scanning, if required. In the case of aneurysmal rupture, emergency $\mathrm{CT}$ scanning is widely used to confirm the diagnosis and enable the planning of aneurysm repair. Following trials of ultrasound screening, screening programmes to reduce male mortality from AAA have been recommended (Cosford 2007; LeFevre 2014). An example is the UK screening programme in which an ultrasound is offered to all men in their $65^{\text {th }}$ year. Following an initial scan, individuals can be entered into regular surveillance if a small AAA is detected, while those with AAA larger than $5.4 \mathrm{~cm}$ can be referred for surgical evaluation (UK NSC 2017). A very similar programme is effective in Sweden, whereas screening is focused on older male smokers in the USA.

Because the risk of rupture is low in small AAA $(\leq 5.5 \mathrm{~cm})$, management is usually non-surgical, using regular ultrasound monitoring to screen for expansion of the aneurysm as well as modifying general cardiovascular risk factors, in particular smoking cessation (Bown 2013; Brewster 2003; Filardo 2015; Hirsch 2006; Moll 2011). Medical therapies to reduce aneurysm growth rates are currently not widely used in clinical practice (Rughani 2012). National guidelines from the European Society of Vascular Surgery (ESVS) and from the American College of Cadiology (ACC) and American Heart Association (AHA) recommend that: when an AAA reaches a diameter of $\geq 5.5 \mathrm{~cm}$ (men) or $\geq 5.2 \mathrm{~cm}$ (women), demonstrates rapid expansion, or becomes symptomatic (regardless of size), the risk of rupture exceeds the risk of surgical repair and the individual should be referred to a vascular surgeon for consideration of surgical intervention (Hirsch 2006; Moll 2011). There are two main options for surgical intervention: open surgical repair (OSR) and endovascular aneurysm repair (EVAR). OSR involves replacement of the affected section of the aorta with a graft that is sutured in place. EVAR involves insertion of an intraluminal stent, via a catheter introduced in a distal artery (e.g. femoral artery). More recently, an alternative endovascular procedure called endovascular sealing is being evaluated: two grafts are introduced, one through each iliac artery, each attached to a bag of polymer that is used to completely seal the aneurysm sac. The main risks of OSR are perioperative cardiac events, infection and death. OSR has a higher 30-day mortality than endovascular stenting (3.0\% versus $0.6 \%$, respectively) (Waton 2018), but is prone to endoleak (blood flow in the remaining aneurysm) in the long term, which requires regular follow-up to detect and possible further surgery to treat (Greenhalgh 2010; Paravastu 2014; Patel 2016; Prinssen 2004). The choice of which surgical intervention to undertake is usually made on an individual basis, taking into account perioperative comorbidities (in particular, cardiac and respiratory conditions) and the individual risk of rupture. The anatomy of the aneurysm is also important because EVAR grafts are only suitable for particular anatomical configurations. Complications include cardiac problems, respiratory problems, haemorrhage, limb ischaemia and renal failure. People undergoing open repair are more susceptible to these complications than those undergoing EVAR (Waton 2018).

\section{Description of the intervention}

The majority of people with indications for elective AAA repair are older adults (Forsdahl 2009; Howard 2015; Kent 2010; Li 2013), who often present with multiple comorbidities (Mousa 2016). In addition to a common history of smoking (Jahangir 2015; Salzler 2015), and sedentary lifestyle, these people tend to have lower fitness levels compared to their age-matched controls (Myers 2014). Significant perioperative metabolic, cardiopulmonary and neuroendocrine challenges are associated with AAA repair (OSR or EVAR), which require the individual undergoing the procedure to have a good level of fitness to withstand the stress. There is evidence that level of fitness is associated with important perioperative and postoperative morbidity and mortality rates in people undergoing AAA repair (Moran 2016).

Exercise therapy is a prescribed and planned physical activity which aims to improve, maintain, or decrease the rate of 
decline of physical capacity and function, as well as overall health and well being. Exercise therapy is routinely used in the management of many long-term conditions, such as cardiovascular diseases. In people with cardiovascular disease who are not undergoing surgery, exercise therapy has been shown to be beneficial in improving fitness and reducing morbidity and mortality risks (Boden 2014). Evidence also supports the use of exercise therapy to improve recovery, as well as to reduce perioperative and postoperative complications and length of hospital stay following cardiovascular surgeries (Hoogeboom 2014). This includes interventions for vascular conditions (Aherne 2015). Exercise therapy for cardiovascular conditions is safe, with the rate of adverse events ranging from 1 per 49,565 patient-hours of exercise training in cardiac patients (Pavy 2006), to 1 per 10,340 patient-hours in peripheral arterial disease (Gommans 2015).

\section{How the intervention might work}

Undergoing surgery promotes an inflammatory response, which increases the demand for oxygen consumption (Barakat 2015). Exercise improves cardiorespiratory fitness, which improves oxygen delivery to local tissue (Smith 2009), and is also associated with anti-inflammatory mechanisms (Petersen 2005). Older 2013 hypothesised that increased lactate production due to lower levels of cardiorespiratory fitness may contribute to postoperative complications, as the body has a reduced ability to metabolise lactate postoperatively.

Optimal fitness potentially provides people with the ability to withstand the metabolic, neuroendocrine and cardiopulmonary stress associated with surgery. Improved cardiovascular and respiratory fitness, and the potential benefit of improved response to surgery-related stress, may be the causal mechanism for the benefit of exercise in people undergoing AAA repair (Grant 2015; Prentis 2012; Thompson 2011).

\section{Why it is important to do this review}

Perioperative and postoperative morbidity and mortality are common following elective repair in people with AAA. There is a growing interest in the role of preoperative exercise therapy for people with AAA undergoing elective repair. Three previous reviews have been conducted on the impact of exercise in people with AAA (Kato 2019; Pouwels 2015; Wee 2019). However, these reviews focused on heterogeneous populations with or without indications for surgery. The outcomes of preoperative exercise therapy for people undergoing AAA repair is unclear from these reviews. If preoperative exercise decreases complications and the length of hospital stay, there is a potential for cost savings. We will perform a systematic review to synthesise evidence about the impact of exercise therapy prior to repair on mortality and morbidity in individuals with AAA. We will also evaluate the impact of different forms of exercise therapy, and investigate if the effect of exercise therapy is influenced by the subsequent type of repair. The findings of this review will provide evidence to help aid decision making and inform practice, with the aim of reducing the high risk of perioperative and preoperative events associated with AAA repair.

\section{O B J E C T IVES}

To assess the effects of exercise programmes on perioperative and postoperative morbidity and mortality associated with abdominal aortic aneurysm repair.

\section{METHODS}

\section{Criteria for considering studies for this review}

\section{Types of studies}

We will include randomised control trials (RCTs) that compare exercise therapy with usual care (no exercise) before elective abdominal aortic aneurysm (AAA) repair.

\section{Types of participants}

We will include participants aged 18 years and older, of either sex, with clinically diagnosed AAA deemed suitable for elective intervention (open surgical repair (OSR) or endovascular aneurysm repair (EVAR)). We will not apply restrictions on the size of the aneurysm. We will exclude studies that only involve participants undergoing emergency repair. If a study includes both elective and emergency participants, we will extract data for the elective participants only, if the trial reports these separately.

\section{Types of interventions}

We will include any exercise therapy before elective AAA repair, provided that the trial compared it against no exercise therapy. The exercise therapy may be in hospital, community or home-based settings. We will include, but not limit to, variations of exercise therapy, such as circuit training, moderate-intensity continuous exercise, high-intensity interval training, and inspiratory muscle training. We will include upper limb and lower limb exercises, as well as both aerobic and strength training programmes. We will include studies that combine exercise with other interventions (e.g. psychological counselling, structured education or behaviour change interventions) if both exercise and no exercise study arms received the same additional interventions, and multi-arm studies that compare exercise with no exercise and other interventions if data are available for the exercise versus no exercise comparison.

We will include both supervised and unsupervised exercise, and will not limit exercise to any frequency, duration, or intensity, but will take these variations into account in the meta-analysis. This review will also consider analysing supervised versus unsupervised exercise in the meta-analysis.

We define a supervised exercise therapy group as one in which participants undergo a programme of exercise delivered and formally supervised by a trained health professional. We define a unsupervised exercise therapy group as one in which participants receive advice to exercise without supervision (with or without a predetermined exercise regimen or logbook), or receive advice to exercise on their own, with regular contact and exercise support from trained personnel (structural home-based exercise programme). We define a no exercise group as one in which the participants maintain normal physical activity. We will aim to analyse supervised and unsupervised therapy where possible.

\section{Types of outcome measures}

\section{Primary outcomes}

- 30-day (or longer if reported) mortality post-AAA repair

- Incidence of perioperative and postoperative complications (cardiac, pulmonary, renal, infection, organ support, and reintervention) 


\section{Secondary outcomes}

- Length of intensive care unit (ICU) recovery

- Length of hospital stay

- Number of ventilator days

- Change in aneurysm size pre- and post-exercise

- Quality of life (QoL, assessed using validated physical summary score scales such as Short Form 12 (SF-12) Health Survey (Ware 1996), Medical Outcomes Study (MOS) 36-Item ShortForm Health Survey (SF-36) (Ware 1992), and Assessment of Quality of Life (AQoL) instruments (AQoL-8D, 7D, 6D or 4D) (Hawthorne 1999).

We will report these outcomes at the last follow-up presented by the included studies. We will also report on adherence to exercise, if the included studies present this.

\section{Search methods for identification of studies}

\section{Electronic searches}

The Cochrane Vascular Information Specialist aims to identify all relevant RCTs regardless of language or publication status (published, unpublished, in press, or in progress).

The Information Specialist will search the following databases for relevant trials:

- the Cochrane Vascular Specialised Register via the Cochrane Register of Studies (CRS-Web);

- the Cochrane Central Register of Controlled Trials (CENTRAL) via the Cochrane Register of Studies Online (CRSO);

- MEDLINE (Ovid MEDLINE ${ }^{\circledR}$ Epub Ahead of Print, In-Process \& Other Non-Indexed Citations, Ovid MEDLINE ${ }^{\circledR}$ Daily and Ovid MEDLINE $^{\circledR}$ ) (1946 onwards);

- Embase Ovid (from 1974 onwards);

- CINAHL EBSCO (Cumulative Index to Nursing and Allied Health Literature; from 1982 onwards);

- PEDro (Physiotherapy Evidence Database), University of Sydney.

The Information Specialist has devised a draft search strategy for RCTs for MEDLINE, which is displayed in Appendix 1 . We will use this as the basis for search strategies for the other listed databases.

The Information Specialist will search the following trials registries:

- ClinicalTrials.gov (clinicaltrials.gov);

- World Health Organization International Clinical Trials Registry Platform (who.int/trialsearch).

\section{Searching other resources}

We will examine the included study reports' bibliographies to identify other relevant articles.

\section{Data collection and analysis}

\section{Selection of studies}

We will identify and exclude duplicates and will collate multiple reports of the same study. Two of three review authors (CF, UA, AT) will independently screen the titles and abstracts from the search results, identifying those to be retrieved for full-text review. Two of three review authors (CF, UA, AT) will independently screen the full texts and identify studies for inclusion. We will resolve any disagreement by discussion until we reach a consensus. Where necessary, we will consult a third review author (JM). We will illustrate the study selection process in a PRISMA diagram (Liberati 2009). We will list all articles excluded after full-text assessment in a 'Characteristics of excluded studies' table, and will provide the reasons for their exclusion.

\section{Data extraction and management}

Two of three review authors (CF, UA, AT) will independently extract relevant population and intervention characteristics, outcome data, and risk of bias components from the included studies using a standard data extraction form, which we will pilot on at least one study in the review. We will enter data into Review Manager 5 (RevMan 5, Review Manager 2014). We will resolve any disagreement about data extraction by discussion, and consult a third review author (JM) when necessary.

\section{Assessment of risk of bias in included studies}

Two review authors (CF, UA) will assess the risk of bias for all included studies, using the Cochrane 'Risk of Bias' tool, described in the Cochrane Handbook for Systematic Reviews of Interventions (Higgins 2011). We will judge the risk of bias in the following seven domains to be low, high or unclear.

- Random sequence generation (selection bias)

- Allocation concealment (selection bias)

- Blinding of participants and personnel (performance bias)

- Blinding of outcome assessment (detection bias)

- Incomeplete outcome data (attrition bias)

- Selective outcome reporting (reporting bias)

- Other sources of bias

\section{Measures of treatment effect}

\section{Dichotomous outcomes}

We will calculate risk ratios (RR) for dichotomous data, with $95 \%$ confidence intervals $(\mathrm{Cl})$.

\section{Continuous outcomes}

If studies measure continuous outcomes on the same scale, we will compare the mean difference (MD) in change scores. If studies use different scales to measure the same continuous outcomes, we will calculate the standardised mean difference (SMD). We will use $95 \%$ Cls for all continuous data.

We will narratively describe skewed data reported as medians and interquartile ranges.

\section{Unit of analysis issues}

We will consider each participant as the unit of analysis in the randomised trials. In RCTs with a parallel design, we will take multiple treatment arms into account, when relevant, to avoid double counting. For trials that considered multiple interventions in the same group, we will analyse only the partial data of interest.

\section{Dealing with missing data}

We will analyse the available data and contact trial authors to request missing data (such as the number of screened or randomised participants, lack of data regarding intention-to-treat 
analyses, or data on as-treated or per-protocol analyses) in order to perform our analyses as thoroughly as possible. We will report dropout rates in the 'Characteristics of included studies' table of the review, and will use intention-to-treat analysis. Where possible, we will use the RevMan 5 calculator to calculate missing standard deviations (SD) using other data from the trial, such as Cls. Where this is not possible, and we consider the missing data to introduce serious bias, we will use a sensitivity analysis to explore the impact of including such studies in the overall assessment of results.

\section{Assessment of heterogeneity}

We will inspect forest plots visually to consider the direction and magnitude of effects, and the degree of overlap between Cls. We will quantify inconsistency among the pooled estimates using the ${ }^{2}$ statistic $\left(\mathrm{I}^{2}=((\mathrm{Q}-\mathrm{df}) / \mathrm{Q}) \times 100 \%\right.$, where $\mathrm{Q}$ is the $\mathrm{Chi}^{2}$ statistic and 'df ' represents the degree of freedom) (Higgins 2011). This will illustrate the percentage of the variability in effect estimates that results from heterogeneity rather than sampling error (Higgins 2011). If we identify substantial heterogeneity $\left(I^{2}>50 \%\right)$, we will report it and explore possible causes by prespecified subgroup analysis.

\section{Assessment of reporting biases}

We will assess the presence of publication bias and other reporting bias using funnel plots, if we identify sufficient studies (more than 10) for inclusion in the meta-analysis (Higgins 2011).

\section{Data synthesis}

We will perform statistical analysis using RevMan 5 software (Review Manager 2014). We will undertake meta-analyses where it is meaningful to do so, i.e. if the included studies' treatments, participants, and underlying clinical questions are similar enough for pooling to make sense. We will summarise the data for each study in a forest plot, and present $95 \% \mathrm{Cl}$ for all summary estimates. We will report data narratively if it is not appropriate to combine data in a meta-analysis.

We will perform meta-analyses according to the recommendations in the Cochrane Handbook for Systematic Reviews of Interventions (Higgins 2011). We will consider a fixed-effect model where we find no substantial heterogeneity $(12<50 \%)$. We will use a randomeffects model if we find substantial heterogeneity $\left(I^{2}>50 \%\right)$.

\section{Subgroup analysis and investigation of heterogeneity}

We will perform subgroup analyses to investigate possible reasons for heterogeneity. We plan to carry out subgroup analyses based on:

- participants age ( $<80$ versus $>80$ years) as the over 80 s are known to have higher rates of complications (Sonesson 2018);

- type of repair (OSR versus EVAR);

- type of exercise therapy (e.g. aerobic versus isometric; supervised versus unsupervised).

\section{Sensitivity analysis}

We will conduct sensitivity analyses to establish whether findings are robust by limiting the analyses to studies with low risk of bias in the selection bias domain, the detection bias domain or both. Additionally, where missing data are thought to introduce serious bias, we will explore the impact of including such studies in the overall assessment of results.

\section{Summary of findings and assessment of the certainty of the evidence}

We will create a 'Summary of findings' table to provide the key information presented in the review for the exercise versus no exercise comparison, using GRADEpro software (GRADEpro GDT). We will include the following outcomes, which are of most clinical relevance, in each table:

- 30-day (or longer if reported) mortality post-AAA repair;

- incidence of perioperative and postoperative complications (cardiac, pulmonary, renal, infection and organ support, and reintervention);

- length of ICU recovery;

- length of hospital stay;

- number of ventilator days;

- QoL.

We will assess the certainty of the evidence for each outcome as high, moderate, low or very low, based on the five GRADE considerations of risk of bias, inconsistency, indirectness, imprecision, and publication bias, using the GRADE approach (Atkins 2004). We will base the tables on methods described in Chapters 11 and 12 of the Cochrane Handbook for Systematic Reviews of Interventions, and will justify any departures from the standard methods (Atkins 2004; Higgins 2011). Two of three review authors (CF, UA, AT) will independently judge the certainty of the evidence and, if required, will resolve any disagreements by consensus or discussion with a third review author (JM). We will justify all decisions to downgrade the evidence using footnotes and we will make comments to aid the reader's understanding of the review where necessary. We have included a draft 'Summary of findings' table in this protocol (Table 1$)$.

\section{ACKNOWLEDGEMENTS}

We would like to acknowledge the support of the Cochrane Vascular Group Editorial Base.

The review authors, and the Cochrane Vascular Editorial Base, are grateful to the following peer reviewers for their time and comments.

Joanne Palmer, Vascular Department, Hull Royal Infirmary, UK Jonathan Moran, Depatment of Physiotherapy, St. James's Hospital, Dublin, Ireland

Dr Thomas Michael Aherne, Department of Vascular Surgery, Beaumont Hospital and Royal College of Surgeons in Ireland, Dublin, Ireland 


\section{REFERE N CES}

\section{Additional references}

\section{Aherne 2015}

Aherne T, McHugh S, Kheirelseid EA, Lee MJ, McCaffrey N, Moneley D, et al. Comparing supervised exercise therapy to invasive measures in the management of symptomatic peripheral arterial disease. Surgery Research and Practice 2015:960402.

\section{Anjum 2012}

Anjum A, von Allmen R, Greenhalgh R, Powell JT. Explaining the decrease in mortality from abdominal aortic aneurysm rupture. British Journal of Surgery 2012 May;99(5):637-45.

\section{Ashton 2002}

Ashton HA, Buxton MJ, Day NE, Kim LG, Marteau TM, Scott RA. The Multicentre Aneurysm Screening Study (MASS) into the effect of abdominal aortic aneurysm screening on mortality in men: a randomised controlled trial. Lancet 2002;360(9345):1531-9.

\section{Ashton 2007}

Ashton HA, Gao L, Kim LG, Druce PS, Thompson SG, Scott RA. Fifteen-year follow-up of a randomized clinical trial of ultrasonographic screening for abdominal aortic aneurysms. British Journal of Surgery 2007;94(6):696-701.

\section{Atkins 2004}

Atkins D, Best D, Briss PA, Eccles M, Falck-Ytter Y, Flottorp S, et al. Grading quality of evidence and strength of recommendations. BMJ 2004;328(7454):1490-4.

\section{Barakat 2015}

Barakat HM, Shahin Y, McCollum PT, Chetter IC. Prediction of organ-specific complications following abdominal aortic aneurysm repair using cardiopulmonary exercise testing. Anaesthesia 2015;70(6):679-85.

\section{Blanchard 2000}

Blanchard JF, Armenian HK, Friesen PP. Risk factors for abdominal aortic aneurysm: results of a case-control study. American Journal of Epidemiology 2000;151(6):575-83.

\section{Boden 2014}

Boden WE, Franklin B, Berra K, Haskell WL, Calfas KJ, Zimmerman $\mathrm{FH}$, et al. Exercise as a therapeutic intervention in patients with stable ischemic heart disease: an underfilled prescription. American Journal of Medicine 2014;127(10):905-11.

\section{Bown 2013}

RESCAN Collaborators, Bown MJ, Sweeting MJ, Brown LC, Powell JT, Thompson SG. Surveillance intervals for small abdominal aortic aneurysms: a meta-analysis. Journal of the American Medical Association 2013 Feb 27;309(8):806-13.

\section{Brewster 2003}

Brewster DC, Cronenwett JL, Hallett JW, Johnston KW, Krupski WC, Matsumura JS. Guidelines for the treatment of abdominal aortic aneurysms. Report of a subcommittee of the
Joint Council of the American Association for Vascular Surgery and Society for Vascular Surgery. Journal of Vascular Surgery 2003;37(5):1106-17.

\section{Brown 2012}

Brown LC, Powell JT, Thompson SG, Epstein DM, Sculpher MJ, Greenhalgh RM. The UK EndoVascular Aneurysm Repair (EVAR) trials: randomised trials of EVAR versus standard therapy. Health Technology Assessment 2012;16(9):1-218.

\section{Cosford 2007}

Cosford PA, Leng GC, Thomas J. Screening for abdominal aortic aneurysm. Cochrane Database of Systematic Reviews 2007, Issue 2. [DOI: 10.1002/14651858.CD002945.pub2]

\section{Filardo 2015}

Filardo G, Powell JT, Martinez MA, Ballard DJ. Surgery for small asymptomatic abdominal aortic aneurysms. Cochrane Database of Systematic Reviews 2015, Issue 2. [DOI: 10.1002/14651858.CD001835.pub4]

\section{Forsdahl 2009}

Forsdahl SH, Singh K, Solberg S, Jacobsen BK. Risk factors for abdominal aortic aneurysms: a 7-year prospective study: the Tromsø study, 1994-2001. Circulation 2009;119:2202-8.

\section{Gommans 2015}

Gommans LN, Fokkenrood HJ, van Dalen HC, Scheltinga MR, Teijink JA, Peters RJ. Safety of supervised exercise therapy in patients with intermittent claudication. Journal of Vascular Surgery 2015;61(2):512-518.

\section{GRADEpro GDT [Computer program]}

McMaster University (developed by Evidence Prime) GRADEpro GDT. Hamilton (ON): McMaster University (developed by Evidence Prime).Available at gradepro.org.

\section{Grant 2015}

Grant SW, Hickey GL, Wisely NA. Cardiopulmonary exercise testing and survival after elective abdominal aortic aneurysm repair. British Journal of Anaesthesia 2015;114:430-436.

\section{Greenhalgh 2010}

Greenhalgh RM, Brown LC, Powell JT, Thompson SG, Epstein D, Sculpher MJ. Endovascular versus open repair of abdominal aortic aneurysm. New England Journal of Medicine 2010;362(20):1863-71.

\section{Gunnarsson 2016}

Gunnarsson K, Wanhainen A, Djavani Gidlund K, Björck M, Mani K. Endovascular versus open repair as primary strategy for ruptured abdominal aortic aneurysm: a national populationbased study. European Journal of Vascular and Endovascular Surgery 2016;51(1):22-8.

\section{Hawthorne 1999}

Hawthorne G, Richardson J, Osborne R. The Assessment of Quality of Life (AQoL) instrument: a psychometric measure 
of health-related quality of life. Quality of Life Research 1999;8(3):209-224.

\section{Higgins 2011}

Higgins JP, Green S, editor(s). Cochrane Handbook for Systematic Reviews of Interventions Version 5.1 (updated March 2011). The Cochrane Collaboration, 2011. Available from handbook.cochrane.org.

\section{Hirsch 2006}

Hirsch AT, Haskal ZJ, Hertzer NR, Bakal CW, Creager MA, Halperin JL et al. ACC/AHA 2005 Practice Guidelines for the management of patients with peripheral arterial disease (lower extremity, renal, mesenteric, and abdominal aortic): a collaborative report from the American Association for Vascular Surgery/Society for Vascular Surgery, Society for Cardiovascular Angiography and Interventions, Society for Vascular Medicine and Biology, Society of Interventional Radiology, and the ACC/ AHA Task Force on Practice Guidelines (Writing Committee to Develop Guidelines for the Management). Circulation 2006;113(11):e463-654.

\section{Hoogeboom 2014}

Hoogeboom TJ, Dronkers JJ, Hulzebos EH, van Meeteren NL. Merits of exercise therapy before and after major surgery. Current Opinion in Anaesthesiology 2014;27(2):161-6.

\section{Howard 2015}

Howard DP, Banerjee A, Fairhead JF, Handa A, Silver LE, Rothwell PM. Age-specific incidence, risk factors and outcome of acute abdominal aortic aneurysms in a defined population. British Journal of Surgery 2015;102(8):907-15.

\section{Jacomelli 2016}

Jacomelli J, Summers L, Stevenson A, Lees T, Earnshaw JJ. Impact of the first 5 years of a national abdominal aortic aneurysm screening programme. British Journal of Surgery 2016 Aug;103(9):1125-31.

\section{Jahangir 2015}

Jahangir E, Lipworth L, Edwards TL, Kabagambe EK, Mumma MT, Mensah GA, et al. Smoking, sex, risk factors and abdominal aortic aneurysms. Journal of Epidemiology and Community Health 2015;69(5):481-8.

\section{Kato 2019}

Kato M, Kubo A, Green FN, Takagi H. Meta-analysis of randomized controlled trials on safety and efficacy of exercise training in patients with abdominal aortic aneurysm. Journal of Vascular Surgery 2019;63(3):933-43.

\section{Kent 2010}

Kent KC, Zwolak RM, Egorova NN, Riles TS, Manganaro A, Moskowitz AJ, et al. Analysis of risk factors for abdominal aortic aneurysm in a cohort of more than 3 million individuals. Journal of Vascular Surgery 2010;2(3):539-48.

\section{Larsson 2009}

Larsson E, Granath F, Swedenborg J, Hultgren R. A populationbased case-control study of the familial risk of abdominal aortic aneurysm. Journal of Vascular Surgery 2009;49(1):47-50; discussion 51.

\section{Lederle 1997}

Lederle FA, Johnson GR, Wilson SE, Chute EP, Littooy FN, Bandyk D, et al. Aneurysm Detection and Management (ADAM) Veterans Affairs Cooperative Study Group. Prevalence and associations of abdominal aortic aneurysm detected through screening. Annals of Internal Medicine 1997;126:441-9.

\section{Lederle 2000}

Lederle FA, Wilson SE, Johnson GR, Reinke DB, Littooy FN Acher CW, et al. Immediate repair compared with surveillance of small abdominal aortic aneurysms. New England Journal of Medicine 2002;346:1437-44.

\section{LeFevre 2014}

LeFevre ML. Screening for abdominal aortic aneurysm: U.S. Preventive Services Task Force recommendation statement. Annals of Internal Medicine 2014;161(4):281-90.

\section{Li 2013}

Li X, Zhao G, Zhang J, Duan Z, Xin S. Prevalence and trends of the abdominal aortic aneurysms epidemic in general population - a meta-analysis. PLoS ONE 2013;8(12):e81260.

\section{Liberati 2009}

Liberati A, Altman DG, Tetzlaff J, Mulrow C, Gotzsche PC, loannidis JP, et al. The PRISMA statement for reporting systematic reviews and meta-analyses of studies that evaluate health care interventions: explanation and elaboration. PLOS Medicine 2009;6:e1000100.

\section{Lindholt 2005}

Lindholt JS, Juul S, Fasting H, Henneberg EW. Screening for abdominal aortic aneurysms: single centre randomised controlled trial. BMJ 2005;330:750.

\section{Moll 2011}

Moll FL, Powell JT, Fraedrich G, Verzini F, Haulon S, Waltham M, et al. Management of Abdominal Aortic Aneurysms Clinical Practice Guidelines of the European Society for Vascular Surgery. European Journal of Vascular and Endovascular Surgery 2011;41:S1eS58.

\section{Moran 2016}

Moran J, Wilson F, Guinan E, McCormick P, Hussey J, Moriarty J. Role of cardiopulmonary exercise testing as a riskassessment method in patients undergoing intra-abdominal surgery: a systematic review. British Journal of Anaesthesia 2016;116(2):177-91.

\section{Mousa 2016}

Mousa AY, Bozzay J, Yacoub M, Stone PA, Najundappa A, Bates MC, et al. Novel risk score model for prediction of survival following elective endovascular abdominal aortic aneurysm repair. Vascular and Endovascular Surgery 2016;116(2):261-9. 


\section{Myers 2014}

Myers J, Kaykha A, George S, Abella J, Zaheer N, Lear S, et al. Fitness versus physical activity patterns in predicting mortality in men. American Journal of Medicine 2004;117(12):912-8.

\section{Nordon 2011}

Nordon IM, Hinchliffe RJ, Loftus IM, Thompson MM. Pathophysiology and epidemiology of abdominal aortic aneurysms. Nature Reviews Cardiology 2011;8:92-102.

\section{Norman 2004}

Norman PE, Jamrozik K, Lawrence-Brown MM, Le MT, Spencer CA, Tuohy RJ, et al. Population based randomised controlled trial on impact of screening on mortality from abdominal aortic aneurysm. BMJ 2004;329(7477):1259.

\section{Older 2013}

Older P. Anaerobic threshold, is it a magic number to determine fitness for surgery? Perioperative Medicine 2013;21(2):1.

\section{Paravastu 2014}

Paravastu SC, Jayarajasingam R, Cottam R, Palfreyman SJ, Michaels JA, Thomas SM. Endovascular repair of abdominal aortic aneurysm. Cochrane Database of Systematic Reviews 2014, Issue 1. [DOI: 10.1002/14651858.CD004178.pub2]

\section{Patel 2016}

Patel R, Sweeting MJ, Powell JT, Greenhalgh RM, EVAR trial investigators. Endovascular versus open repair of abdominal aortic aneurysm in 15-years' follow-up of the UK endovascular aneurysm repair trial 1 (EVAR trial 1): a randomised controlled trial. Lancet 2016;388(10058):2366-2374.

\section{Pavy 2006}

Pavy B, lliou MC, Meurin P, Tabet JY, Corone S. Functional evaluation and cardiac rehabilitation Working Group of the French Society of Cardiology safety of exercise training for cardiac patients: results of the French registry of complications during cardiac rehabilitation. Archives of Internal Medicine 2006;166(21):2329-34.

\section{Petersen 2005}

Petersen AM, Pedersen BK. The anti-inflammatory effect of exercise. Journal of Applied Physiology (Bethesda, Md. : 1985) 2005;98(4):1154-62.

\section{Pouwels 2015}

Pouwels S, Willigendael EM, van Sambeek MR, Nienhuijs SW, Cuypers PW, Teijink JA. Beneficial effects of pre-operative exercise therapy in patients with an abdominal aortic aneurysm: a systematic review. European Journal of Vascular and Endovascular Surgery 2015;49(1):66-76.

\section{Powell 2008}

Powell JT, Brown LC, Greenhalgh RM, Thompson SG. The rupture rate of large abdominal aortic aneurysms: is this modified by anatomical suitability for endovascular repair? Annals of Surgery 2008;247(1):173-9.

\section{Powell 2011}

Powell JT, Gotensparre SM, Sweeting MJ, Brown LC, Fowkes FG, Thompson SG. Rupture rates of small abdominal aortic aneurysms: a systematic review of the literature. European Journal of Vascular and Endovascular Surgery 2011 Jan;41(1):2-10.

\section{Prentis 2012}

Prentis JM, Trenell MI, Jones, DJ. Submaximal exercise testing predicts perioperative hospitalization after aortic aneurysm repair. Journal of Vascular Surgery 2012;56:1564-1570.

\section{Prinssen 2004}

Prinssen M, Verhoeven EL, Buth J, Cuypers PW, van Sambeek MR, Balm R, et al, on behalf of the Dutch Randomized Endovascular Aneurysm Management (DREAM) Trial Group. A randomized trial comparing conventional and endovascular repair of abdominal aortic aneurysms. New England Journal of Medicine 2004;351(16):1607-18.

\section{Review Manager 2014 [Computer program]}

Nordic Cochrane Centre, The Cochrane Collaboration Review Manager 5 (RevMan 5). Version 5.3. Copenhagen: Nordic Cochrane Centre, The Cochrane Collaboration, 2014.

\section{Rughani 2012}

Rughani G, Robertson L, Clarke M. Medical treatment for small abdominal aortic aneurysms. Cochrane Database of Systematic Reviews 2012, Issue 9. [DOI: 10.1002/14651858.CD009536.pub2]

\section{Salzler 2015}

Salzler GG, Meltzer AJ, Mao J, Isaacs A, Connolly PH, Schneider DB, et al. Characterizing the evolution of perioperative outcomes and costs of endovascular abdominal aortic aneurysm repair. Journal of Vascular Surgery 2015;62(5):1134-9.

\section{Schermerhorn 2012}

Schermerhorn ML, Bensley RP, Giles KA, Hurks R, O'malley AJ, Cotterill $P$, et al. Changes in abdominal aortic aneurysm rupture and short-term mortality, 1995-2008: a retrospective observational study. Annals of Surgery 2012;256(4):651-8.

\section{Scott 2002}

Scott RA, Bridgewater SG, Ashton HA. Randomized clinical trial of screening for abdominal aortic aneurysm in women. British Journal of Surgery 2002;89:283-5.

\section{Smith 2009}

Smith TB, Stonell C, Purkayastha S, Paraskevas P. Cardiopulmonary exercise testing as a risk assessment method in non cardio-pulmonary surgery: a systematic review. Anaesthesia 2009;64(8):883-93.

\section{Sonesson 2018}

Sonesson B, Dias N, Resch T. Is there an age limit for abdominal aortic aneurysm repair? Journal of Cardiovascular Surgery 2018;59(2):190-194. 


\section{Spark 2001}

Spark JI, Baker JL, Vowden P, Wilkinson D. Epidemiology of abdominal aortic aneurysms in the Asian community. British Journal of Surgery 2001;88(3):382-4.

\section{Svensjö 2014}

Svensjö S, Mani K, Björck M, Lundkvist J, Wanhainen A. Screening for abdominal aortic aneurysm in 65-year-old men remains cost-effective with contemporary epidemiology and management. European Journal of Vascular and Endovascular Surgery 2014;47(4):357-65.

\section{Sweeting 2015}

Sweeting MJ, Balm R, Desgranges P, Ulug P, Powell JT. Ruptured Aneurysm Trialists. Individual-patient meta-analysis of three randomized trials comparing endovascular versus open repair for ruptured abdominal aortic aneurysm. British Journal of Surgery 2015;102(10):1229-39.

\section{Thompson 2011}

Thompson AR, Peters N, Lovegrove RE. Cardiopulmonary exercise testing provides a predictive tool for early and late outcomes in abdominal aortic aneurysm patients. Annals of the Royal Collage of Surgery England 2011;93:474-481.

\section{UK NSC 2017}

UK NSC. The UK NSC recommendation on Abdominal Aortic Aneurysm screening in men over 65; 2017. legacyscreening.phe.org.uk/aaa.

\section{Ulug 2016}

Ulug P, Powell JT, Sweeting MJ, Bown MJ, Thompson SG, SWAN Collaborative Group. Meta-analysis of the current prevalence of screen-detected abdominal aortic aneurysm in women. British Journal of Surgery 2016;103(9):1097-104.

\section{Vardulaki 1999}

Vardulaki KA, Prevost TC, Walker NM, Day NE, Wilmink AB, Quick CR, et al. Incidence among men of asymptomatic aortic abdominal aneurysms: estimates from 500 screen detected cases. Journal of Medical Screening 1999;6(1):50-4.

\section{Ware 1992}

Ware J, Sherbourne CD. The MOS 36-item short-form health survey (SF-36): I. Conceptual framework and item selection. Medical care 1992;30(6):473-483.

\section{Ware 1996}

Ware JE, Kosinski M, Keller SD. A 12-Item Short-Form Health Survey: construction of scales and preliminary tests of reliability and validity. Medical care 1996;34(3):220-233.

\section{Waton 2018}

Waton S, Johal A, Heikkila K, Cromwell D, Boyle J, Miller F. National Vascular Registry: 2018 annual report. London: The Royal College of Surgeons of England, 2018.

\section{Wee 2019}

Wee IJ, Choong AM. A systematic review of the impact of preoperative exercise for patients with abdominal aortic aneurysms. Journal Vascular Surgery 2019;71(6):2123-2131.e1. [DOI: 10.1016/j.jvs.2018.09.039]

\section{Wild 2013}

Wild JB, Stather PW, Biancari F, Choke EC, Earnshaw JJ, Grant SW, et al. A multicentre observational study of the outcomes of screening detected sub-aneurysmal aortic dilatation. European Journal of Vascular and Endovascular Surgery 2013;45(2):128-34.

\section{ADDITIONAL TABLES}

\section{Table 1. Draft 'Summary of findings' table}

Exercise programmes compared with no exercise programmes before AAA repair

Patient or population: people who have undergone repair for AAA

Settings: hospital, community or home-based settings

Intervention: exercise programme ${ }^{a}$

Comparison: no exercise programme ${ }^{b}$

\begin{tabular}{|c|c|c|c|c|c|c|}
\hline \multirow[t]{2}{*}{ Outcomes } & \multicolumn{2}{|c|}{ Anticipated absolute effects ${ }^{\star}(95 \% \mathrm{Cl})$} & \multirow{2}{*}{$\begin{array}{l}\text { Rela- } \\
\text { tive } \\
\text { effect } \\
(95 \% \\
\mathrm{CI})\end{array}$} & \multirow{2}{*}{$\begin{array}{l}\text { No of } \\
\text { Par- } \\
\text { tici- } \\
\text { pants } \\
\text { (stud- } \\
\text { ies) }\end{array}$} & \multirow{2}{*}{$\begin{array}{l}\text { Certainty of the evidence } \\
\text { (GRADE) }\end{array}$} & \multirow{2}{*}{$\begin{array}{l}\text { Com- } \\
\text { ments }\end{array}$} \\
\hline & $\begin{array}{l}\text { Risk with no exer- } \\
\text { cise programme }\end{array}$ & $\begin{array}{l}\text { Risk with exercise pro- } \\
\text { gramme }\end{array}$ & & & & \\
\hline \multirow{2}{*}{$\begin{array}{l}30 \text { day (or longer if } \\
\text { reported) mortali- } \\
\text { ty post-AAA repair }\end{array}$} & Study population & & \multirow{2}{*}{$\begin{array}{l}\text { RR } \\
\text { [val- } \\
\text { ue] } \\
\text { ([val- }\end{array}$} & \multirow{2}{*}{$\begin{array}{l}\text { [val- } \\
\text { ue] } \\
\text { ([val- } \\
\text { ue]) }\end{array}$} & \multirow{2}{*}{$\begin{array}{l}\text { [Delete as } \\
\text { appropriate] }\end{array}$} & \\
\hline & [value] per 1000 & $\begin{array}{l}\text { [value] per } \mathbf{1 0 0 0} \\
\text { ([value] to [value]) }\end{array}$ & & & & \\
\hline
\end{tabular}


Table 1. Draft 'Summary of findings' table (Continued)

$\begin{array}{ll}\begin{array}{ll}\text { ue] to } \\ \text { [val- } \\ \text { ue]) }\end{array} & \oplus \oplus \ominus \ominus \\ & \text { low } \\ & \oplus \oplus \oplus \odot \\ & \text { moderate } \\ & \oplus \oplus \oplus \oplus \\ \text { high }\end{array}$

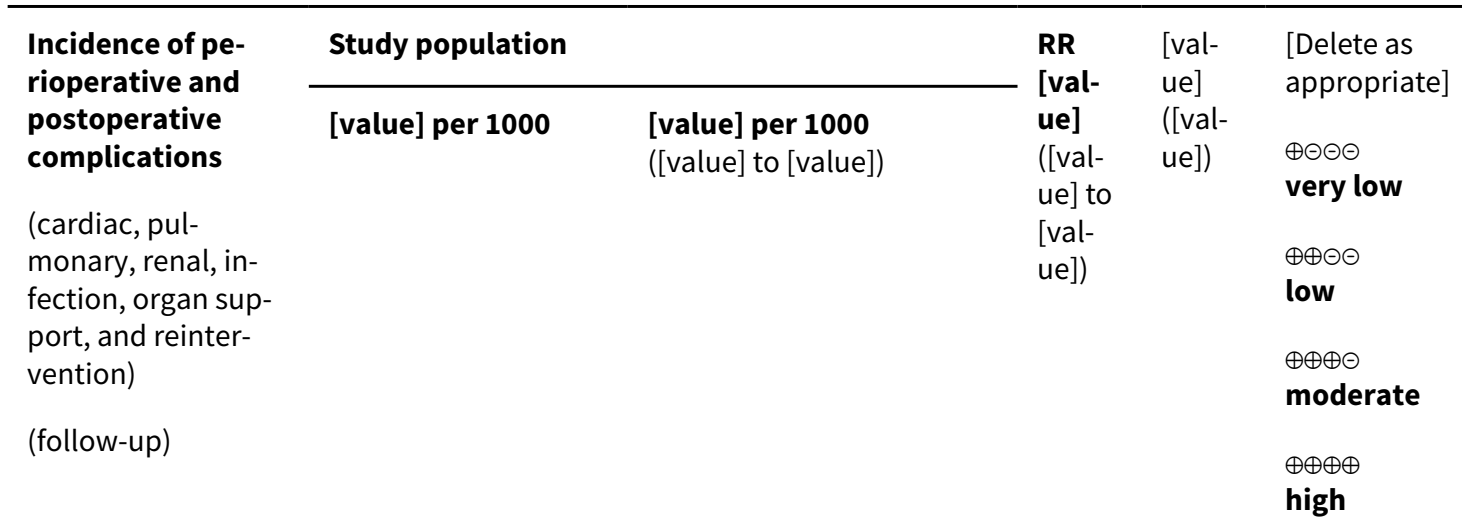

\begin{tabular}{|c|c|c|c|c|c|}
\hline $\begin{array}{l}\text { Length of ICU re- } \\
\text { covery } \\
\text { (follow-up) }\end{array}$ & $\begin{array}{l}\text { The mean [outcome] } \\
\text { ranged across con- } \\
\text { trol groups from } \\
\text { [value][measure] }\end{array}$ & $\begin{array}{l}\text { The mean [outcome] in } \\
\text { the intervention groups } \\
\text { was } \\
\text { [value] [lower/higher] } \\
\text { [(value to value low- } \\
\text { er/higher)] }\end{array}$ & - & $\begin{array}{l}\text { [val- } \\
\text { ue] } \\
\text { ([val- } \\
\text { ue]) }\end{array}$ & 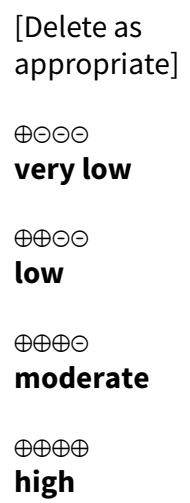 \\
\hline
\end{tabular}

\begin{tabular}{|c|c|c|c|c|c|}
\hline $\begin{array}{l}\text { Length of hospital } \\
\text { stay } \\
\text { (follow-up) }\end{array}$ & $\begin{array}{l}\text { The mean [outcome] } \\
\text { ranged across con- } \\
\text { trol groups from } \\
\text { [value][measure] }\end{array}$ & $\begin{array}{l}\text { The mean [outcome] in } \\
\text { the intervention groups } \\
\text { was } \\
\text { [value] [lower/higher] } \\
\text { [(value to value low- } \\
\text { er/higher)] }\end{array}$ & - & $\begin{array}{l}\text { [val- } \\
\text { ue] } \\
\text { ([val- } \\
\text { ue]) }\end{array}$ & $\begin{array}{l}\text { [Delete as } \\
\text { appropriate] } \\
\oplus \odot \ominus \ominus \\
\text { very low } \\
\oplus \oplus \ominus \ominus \\
\text { low } \\
\oplus \oplus \oplus \ominus \\
\text { moderate } \\
\oplus \oplus \oplus \oplus \\
\text { high }\end{array}$ \\
\hline $\begin{array}{l}\text { Number of ventila- } \\
\text { tor days } \\
\text { (follow-up) }\end{array}$ & $\begin{array}{l}\text { The mean [outcome] } \\
\text { ranged across con- } \\
\text { trol groups from } \\
\text { [value][measure] }\end{array}$ & $\begin{array}{l}\text { The mean [outcome] in } \\
\text { the intervention groups } \\
\text { was } \\
\text { [value] [lower/higher] } \\
\text { [(value to value low- } \\
\text { er/higher)] }\end{array}$ & - & $\begin{array}{l}\text { [val- } \\
\text { ue] } \\
\text { ([val- } \\
\text { ue]) }\end{array}$ & $\begin{array}{l}\text { [Delete as } \\
\text { appropriate] } \\
\oplus \ominus \ominus \ominus \\
\text { very low } \\
\oplus \oplus \ominus \ominus \\
\text { low }\end{array}$ \\
\hline
\end{tabular}


Table 1. Draft 'Summary of findings' table (Continued)

\section{moderate}

$\oplus \oplus \oplus \oplus$

high

\begin{tabular}{|c|c|c|c|c|c|}
\hline $\begin{array}{l}\text { QoL } \\
\text { (using validated } \\
\text { summary score, fol- } \\
\text { low-up) }\end{array}$ & $\begin{array}{l}\text { The mean [outcome] } \\
\text { ranged across con- } \\
\text { trol groups from } \\
\text { [value][measure] }\end{array}$ & $\begin{array}{l}\text { The mean [outcome] in } \\
\text { the intervention groups } \\
\text { was } \\
\text { [value] [lower/higher] } \\
\text { [(value to value low- } \\
\text { er/higher)] }\end{array}$ & - & $\begin{array}{l}\text { [val- } \\
\text { ue] } \\
\text { ([val- } \\
\text { ue]) }\end{array}$ & 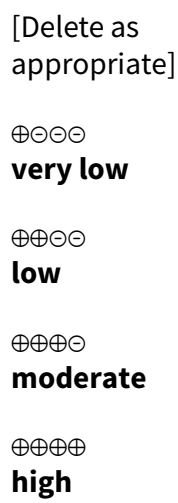 \\
\hline
\end{tabular}

*The risk in the intervention group (and its $95 \%$ confidence interval) is based on the assumed risk in the comparison group and the relative effect of the intervention (and its $95 \% \mathrm{Cl}$ ).

AAA: abdominal aortic aneurysm; Cl: confidence interval; ICU: intensive care unit; QoL: quality of life; RR: risk ratio;

\section{GRADE Working Group grades of evidence}

High certainty: We are very confident that the true effect lies close to that of the estimate of the effect

Moderate certainty: We are moderately confident in the effect estimate: The true effect is likely to be close to the estimate of the ef-

fect, but there is a possibility that it is substantially different

Low certainty: Our confidence in the effect estimate is limited: The true effect may be substantially different from the estimate of the effect

Very low certainty: We have very little confidence in the effect estimate: The true effect is likely to be substantially different from the estimate of effect

$a$ Exercise includes both supervised and unsupervised exercise therapies. Supervised exercise therapy consists of a programme of exercise delivered and formally supervised by a trained health professional. Programme inclusion is not limited by frequency or intensity of the exercise programme. Unsupervised exercise therapy consists of advice to exercise without supervision (with or without a predetermined exercise regimen or logbook), or to exercise on their own with regular contact and exercise support from trained personnel (structural home-based exercise programme).

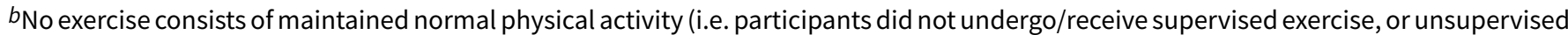
exercise).

\section{AP P E N DICES}

\section{Appendix 1. MEDLINE search strategy}

1 exp Aortic Aneurysm/

2 exp Aneurysm, Ruptured/

3 exp Aorta, Abdominal/

$4 \mathrm{AAA}^{*} . \mathrm{ti}, \mathrm{ab}$.

5 (aneurysm* adj4 (abdom or thoracoabdom* or thoraco-abdom or aort $\left.{ }^{\star}\right)$ ).ti,ab.

6 (aort* adj3 (balloon* or dilat* or bulg*)).ti,ab.

7 (abdom* adj3 (balloon* or dilat* or bulg*)).ti,ab.

8 (aneurism ${ }^{\star}$ adj4 (abdom* or thoracoabdom ${ }^{\star}$ or thoraco-abdom ${ }^{\star}$ or aort $\left.{ }^{\star}\right)$ ).ti,ab. 
9 or $/ 1-8$

10 exp Exercise/

11 exp Exercise Therapy/

12 exp Preoperative Care/

13 "home based train*".ti,ab.

14 "Interval Train*".ti,ab.

15 "Physical activit*".ti,ab.

16 "Physical train^".ti,ab.

17 "Physical Therap*".ti,ab.

18 Exercis $^{\star} . t i, a b$.

19 physiotherapy.ti,ab.

20 prehabilitat*.ti,ab.

21 pre-habilitation.ti,ab.

22 "physical fitness".ti,ab.

23 pre-habilitation.ti,ab.

24 or $/ 10-23$

259 and 24

26 randomized controlled trial.pt.

27 controlled clinical trial.pt.

28 randomized.ab.

29 placebo.ab.

30 drug therapy.fs.

31 randomly.ab.

32 trial.ab.

33 groups.ab.

34 or/26-33

35 exp animals/ not humans.sh.

3634 not 35

3725 and 36

\section{H I S T O R Y}

Protocol first published: Issue 7, 2020

\section{CONTRIBUTIONSOF AUTHORS}

CF: designing and drafting the protocol, designing literature searches, acquiring trial reports, trial selection, data extraction, data analysis, data interpretation, review drafting and future review updates

UA: designing and drafting the protocol, acquiring trial reports, trial selection, data extraction, data analysis, data interpretation, review drafting and future review updates 
AT: designing and drafting the protocol, acquiring trial reports, trial selection, data extraction, data analysis, data interpretation, review drafting and future review updates

JM: designing and drafting the protocol, data interpretation, review drafting and future review updates

\section{DECLARATIONS OF INTEREST}

CF: none known

UA: none known

AT: is employed as a Network Support Fellow for Cochrane (based in University College London). She receives payment from the Royal College of Obstetricians and Gynaecologists for freelance systematic reviewing to develop NICE guidelines.

JM: has declared that he has received travel, course fees, accommodation and meals from Medtronic, Gore, Abbott and Vascutek to attend various educational courses/meetings. He has not received any other financial remuneration. He received speakers fees along with travel and accommodation from Gore to attend/speak at the 2015 VSGBI meeting and other educational events. He is a cofounder of UKETS, a trainee initiative which receives funding through sponsorship from endovascular technology and simulation companies. The majority of this is non-financial (the companies supply trainers on the courses or allow use of their simulators), although Vascutek, Abbott, Cook, Medtronic and Mentice give some direct financial input that is used to run events. JM derives no personal profit from this initiative.

\section{SOURCES OF SUPPORT}

\section{Internal sources}

- No sources of support supplied

\section{External sources}

- Chief Scientist Office, Scottish Government Health Directorates, The Scottish Government, UK

The Cochrane Vascular editorial base is supported by the Chief Scientist Office. 